\title{
Development of educational motivation through the youth socio-cultural, environmental and leisure practices
}

\author{
Vadim Goncharov ${ }^{1}$, Valentina Ivashova ${ }^{2, *}$, Olga Kolosova $^{3}$, Larisa Tronina $^{4}$ and \\ Vyacheslav Berkovsky ${ }^{4}$ \\ ${ }^{1}$ North Caucasus Federal University, 1, Pushkin Street, 355017, Stavropol, Russia \\ ${ }^{2}$ Stavropol State Agrarian University, 12, Zootechnicheskiy Lane, 355017, Stavropol, Russia \\ ${ }^{3}$ Krasnodar University of the Ministry of the Interior of the Russian Federation, Stavropol Branch, 43, \\ Kulakova Street, 355047, Stavropol, Russia \\ ${ }^{4}$ Stavropol State Pedagogical Institution, 417 A, Lenin Street, 355029, Stavropol, Russia
}

\begin{abstract}
The presents the results of a study of the developmental potential of socio-cultural and leisure practices of youth, used in university education to increase educational adaptation and motivation of students. The relevance of the study lies in the identification of new motivational mechanisms that provide more effective educational adaptation and motivation of young people to obtain vocational education. The relevance of the research is confirmed in the substantive discussion of scientists in the field of transformation of cultural and leisure practices and improving the mechanisms of educational motivation in vocational education. The empirical part of the study of the development of educational motivation through socio-cultural and leisure practices, implemented in the university community, was conducted by a questionnaire survey of 458 people from among the students of the Stavropol Territory. The data was processed using the SPSS Statistics program (version 21). Factor analysis was performed by the method of separation of the main components and by the method of rotation - Varimax with Kaiser Normalization. We present the models of socio-cultural activity that contribute to educational adaptation and increase the motivation of professional self-determination and the formation of future specialists.
\end{abstract}

\section{Introduction}

At present, in a number of cases, we observe socially negative facts in the youth environment. Such examples include an increase in the time spent on professional selfdetermination of young people, the manifestation of youthful infantilism, consumer attitude towards others, the absence or weak signs of focus on productive activities that have concrete results within certain time limits, etc. Such even isolated cases in the educational team have a negative effect on educational motivation; reduce the adaptive capabilities of

\footnotetext{
* Corresponding author: vivashov@mail.ru
} 
the social group and the quality of professional knowledge and skills during the period of study at the university.

In this regard, it is relevant to search for new motivational mechanisms that ensure effective educational adaptation, motivation of young people to obtain professional education. These mechanisms should take into account the social reality of modern society, where a significant share of social communications of young people, including educational ones, has been transferred to a virtual environment. Social and cultural activity and participation in creative activities, various types of which are offered to students during their studies at the university, are an important element of the new motivational mechanism. Leisure social and cultural practices of young people can be considered as an important factor in increasing educational motivation during the period of obtaining professional education.

The relevance of the study is confirmed in a substantive discussion of scientists in the field of transformation of cultural and leisure practices and improving the mechanisms of educational motivation in vocational education.

The issues of transforming cultural and leisure activities are considered in the work of the authors L.I. Ermakova, D.N. Sukhovskaya, who analyze the correlation dependences of the forms of leisure of a modern citizen and his/her/their key values in life [1]. The starting point of the researchers' reasoning is the assertion that the content and intensity of the information flow are changing in the digital urban environment, and when it is used in new forms of cultural and leisure activities, it is possible to have a significant impact on the values of the local community. For our study of the possibilities of social, cultural and leisure activities of young people in a positive qualitative impact on learning motivation, an important conclusion can be drawn. Since personality values are the basis of professional self-determination and have a positive effect on educational motivation, therefore, the targeted alignment of socio-cultural and leisure practices during the period of study at the university ensures the development of the creative potential of the individual. It lays the foundation for planning activities, expands real social networks and improves group interaction in the university community.

Researchers M.C. Yang, J.S. Cheng, S.W. Yu analyzed the relationship between leisure patterns and quality of life in terms of health. In the course of factorial and further cluster analysis, the following models were established: commitment to travel, focus on selfrealization, love of physical culture and sports, the prevalence of passive forms of leisure (stay-at-home) and participation in social activities, support of loved ones [2].

The great potential of cultural and leisure activities in ensuring the diversified development of adolescents and young people for their development as mature individuals, integration into society, successful professional self-realization is shown by the authors $\mathrm{V}$. Indrašiene, O. Merfeldaite on the example of the center of children's socialization in Lithuania [3].

Researchers J.V. Kashina, I.V. Gluzman, N.A. Oparina, O.V. Ershova, S.Sh. Umerkaeva in their article showed the results of studying the regulatory and adaptive status of students depending on the types of temperament [4]. In their opinion, learning adaptation and motivation depend on the type of temperament. These issues are being updated in connection with the transition to distance learning in an online format. The key conclusion of the authors is the conclusion that high regulatory and adaptive abilities are observed in phlegmatic and sanguine people, and the lowest among students-melancholic. Thus, innate psychological qualities of a person play an essential role in learning adaptation and motivation of students during the period of distance learning.

The issues of educational adaptation in connection with the commitment of students to different types of social activity are studied by the authors R. Shamionov, M. Grigoryeva, E. Grinina, A. Sozonnik [5]. Researchers have carried out a segmentation of students by the 
level of health: with chronic diseases and without deviations in health. A significant correlation was revealed between educational adaptation and various forms of social activity in the virtual space in groups of students with chronic diseases. In groups of students without deviations in health, successful educational adaptation is associated with real social activities in the field of leisure, culture, and civic activities.

\section{Methods}

To study the process of developing educational motivation through social, cultural and leisure practices implemented in the university community, we carried out a questionnaire survey of young people. A total of 458 students from the Stavropol Territory took part in it. The data was processed using the SPSS Statistics program (version 21).

The questionnaire lists various types of social, cultural and leisure activities, the intensity of participation in which was indicated in the responses of young people. In addition, the survey participants assessed educational adaptation and motivation in the process of obtaining professional education. Factor analysis was performed by the method of separation of the main components and by the method of rotation - Varimax with Kaiser Normalization. We presented the models of socio-cultural activity that contribute to educational adaptation and increase the motivation of professional self-determination and the formatio of future specialists.

\section{Results}

The total explained variance for the student coping category is $62.9 \%$ and is determined by 2 components. The data is presented in Table 1.

Table 1. Total variance explained for the student category (successful in education).

\begin{tabular}{|c|c|c|c|c|c|c|c|c|c|}
\hline \multirow[b]{2}{*}{ 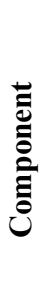 } & \multicolumn{3}{|c|}{ Initial eigenvalues } & \multicolumn{3}{|c|}{$\begin{array}{c}\text { Sums of squares of } \\
\text { extraction loads }\end{array}$} & \multicolumn{3}{|c|}{$\begin{array}{l}\text { Sums of squares of } \\
\text { rotational loads }\end{array}$} \\
\hline & हैं & ○゚ & 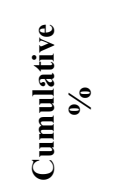 & 矛 & ò & 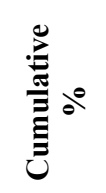 & हैं & बং & 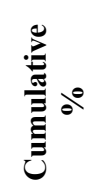 \\
\hline 1 & 3.842 & 48.019 & 48.019 & 3.842 & 48.019 & 48.019 & 2.984 & 37.301 & 37.301 \\
\hline 2 & 1.190 & 14.877 & 62.896 & 1.190 & 14.877 & 62.896 & 2.048 & 25.595 & 62.896 \\
\hline 3 & 0.894 & 11.176 & 74.072 & & & & & & \\
\hline 4 & 0.710 & 8.872 & 82.944 & & & & & & \\
\hline 5 & 0.457 & 5.719 & 88.662 & & & & & & \\
\hline 6 & 0.383 & 4.785 & 93.448 & & & & & & \\
\hline 7 & 0.285 & 3.566 & 97.014 & & & & & & \\
\hline 8 & 0.239 & 2.986 & 100.000 & & & & & & \\
\hline
\end{tabular}

The listed 8 types of social, cultural and leisure activities, the intensity of participation in which was indicated in the responses of students (who successfully cope with the study load), as a result of factor analysis performed by the Rotation Method: Varimax with Kaiser Normalization (Rotation converged in 3 iterations) were grouped into 2 activity factors. 
Table 2. Rotated component matrix for the student category (successful in education).

\begin{tabular}{|l|c|c|}
\hline \multirow{2}{*}{\multicolumn{1}{|c|}{ Types of cultural and leisure activities }} & \multicolumn{2}{c|}{ Component } \\
\cline { 2 - 3 } & $\mathbf{1}$ & $\mathbf{2}$ \\
\hline 1. Walking with friends & $\mathbf{0 . 5 8 6}$ & 0.567 \\
\hline 2. Reading books & -0.127 & $\mathbf{0 . 8 5 8}$ \\
\hline 3. Watching movies & $\mathbf{0 . 5 8 9}$ & 0.464 \\
\hline 4. Online games & $\mathbf{0 . 7 0 6}$ & -0.186 \\
\hline 5. Sports activities & 0.362 & $\mathbf{0 . 6 5 1}$ \\
\hline 6. Communication on social networks & $\mathbf{0 . 6 5 0}$ & 0.401 \\
\hline 7. Watching videos & $\mathbf{0 . 8 4 1}$ & 0.132 \\
\hline 8. Reading the news feed & $\mathbf{0 . 7 2 0}$ & 0.371 \\
\hline
\end{tabular}

By the content of the grouped types of activity, we can say that the first factor is determined by a set of variables: watching videos (load factor $\mathbf{0 . 8 4 1}$ ); reading the news feed (load factor $\mathbf{0 . 7 2 0}$ ); online games (load factor $\mathbf{0 . 7 0 6}$ ); communication in social networks (load factor 0.650); watching films (load factor 0.589); walking with friends (load factor 0.586). Thus, the first factor can be interpreted as a social ecosystem of a person, based mainly on virtual activities.

The second factor is determined by a set of variables: reading books $(\mathbf{0 . 8 5 8})$; sports activities (load factor $\mathbf{0 . 6 5 1}$ ). Thus, the second factor can be interpreted as educational motivation based on personal cognitive interest and supported by a healthy lifestyle.

The total explained variance for the category of students who cannot cope with the workload is $81.6 \%$ and is determined by 2 components. Data is presented in Table 3 .

Table 3. Total variance explained for the category of students who cannot cope with the study load.

\begin{tabular}{|c|c|c|c|c|c|c|c|c|c|}
\hline \multirow[b]{2}{*}{ 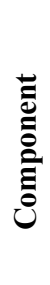 } & \multicolumn{3}{|c|}{ Initial eigenvalues } & \multicolumn{3}{|c|}{$\begin{array}{l}\text { Sums of squares of } \\
\text { extraction loads }\end{array}$} & \multicolumn{3}{|c|}{$\begin{array}{l}\text { Sums of squares of } \\
\text { rotational loads }\end{array}$} \\
\hline & 吾 & 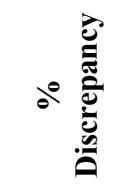 & 胥 & & 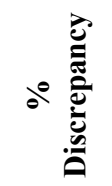 & 胥 & & 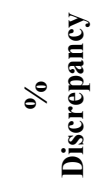 & 总 \\
\hline 1 & 4.240 & 53.000 & 53.000 & 4.240 & 53.000 & 53.000 & 3.758 & 46.979 & 46.979 \\
\hline 2 & 2.291 & 28.633 & 81.633 & 2.291 & 28.633 & 81.633 & 2.772 & 34.654 & 81.633 \\
\hline 3 & 0.878 & 10.978 & 92.612 & & & & & & \\
\hline 4 & 0.442 & 5.523 & 98.134 & & & & & & \\
\hline 5 & 0.149 & 1.866 & 100.000 & & & & & & \\
\hline 6 & $3.518 \mathrm{E}-16$ & $\begin{array}{l}4.397 \mathrm{E}- \\
15\end{array}$ & 100.000 & & & & & & \\
\hline 7 & $3.909 \mathrm{E}-17$ & $\begin{array}{c}4.886 \mathrm{E}- \\
16\end{array}$ & 100.000 & & & & & & \\
\hline 8 & $-1.657 \mathrm{E}-16$ & $\begin{array}{l}-2.072 \mathrm{E}- \\
15\end{array}$ & 100.000 & & & & & & \\
\hline
\end{tabular}

The listed 8 types of social, cultural and leisure activities, the intensity of participation in which was indicated in the answers of students (who cannot cope with the study load) as 
a result of factor analysis performed by the Rotation Method: Varimax with Kaiser Normalization (Rotation converged in 3 iterations) were grouped into 2 activity factors.

Table 4. Rotated component matrix for the category of students who cannot cope with the study load.

\begin{tabular}{|l|c|c|}
\hline \multirow{2}{*}{\multicolumn{1}{|c|}{ Types of cultural and leisure activities }} & \multicolumn{2}{c|}{ Component } \\
\cline { 2 - 3 } & $\mathbf{1}$ & $\mathbf{2}$ \\
\hline 1. Walking with friends & $\mathbf{0 . 9 2 6}$ & -0.301 \\
\hline 2. Reading books & $\mathbf{0 . 8 0 2}$ & -0.330 \\
\hline 3. Watching movies & $\mathbf{0 . 8 1 4}$ & -0.371 \\
\hline 4. Online games & -0.463 & $\mathbf{0 . 7 2 4}$ \\
\hline 5. Sports activities & $\mathbf{0 . 8 6 8}$ & 0.322 \\
\hline 6. Communication on social networks & $\mathbf{0 . 7 5 2}$ & 0.066 \\
\hline 7. Watching videos & 0.181 & $\mathbf{0 . 9 5 9}$ \\
\hline 8. Reading the news feed & 0.172 & $\mathbf{- 0 . 9 4 0}$ \\
\hline
\end{tabular}

According to the content of the grouped types of activity, we can say that the first factor is determined by a set of variables: walking with friends (load factor $\mathbf{0 . 9 2 6}$ ); sports activities (load factor $\mathbf{0 . 8 6 8}$ ); watching films (load factor $\mathbf{0 . 8 1 4}$ ); reading books (load factor 0.802); communication in social networks (load factor $\mathbf{0 . 7 5 2}$ ). Thus, the first factor can be interpreted as suppression of learning motivation by the intensity and variety of leisure activities.

The second factor is determined by a set of variables: watching videos (load factor $\mathbf{0 . 9 5 9}$ ); online games (load factor $\mathbf{0 . 7 2 4}$ ); reading news feed (load factor $\mathbf{- 0 . 9 4 0}$ ). Thus, the second factor can be interpreted as passive individual leisure practices in the virtual space with signs of narrowing of social communications.

\section{Discussion}

The intensity and constructive orientation of social activity in study groups helps to reduce the level of anxiety in adolescents and young people through communicative practices united by educational goals [6]. These conclusions of psychologists help to prove the hypothesis that it is the social activity of young people in the field of culture and leisure that increases educational motivation through a decrease in the level of anxiety and stress [7] and the development of group communication skills. Similar conclusions about the positive impact of a gender-friendly environment and communicative competence of nursing students in the success of educational adaptation were made by the authors of S. Park, J.H. Kim [8].

In connection with the existing reality of distance learning, improving the mechanism of professional adaptation of teachers to digital reality is of decisive importance for improving the quality of education in universities [9]. According to researchers, students prefer passive forms of using information and communication technologies (webinars, online courses). Thus, the task of involving students in interactive digital forms of education, the use of game, team forms on the verge of interactive fascinating leisure, becomes relevant. And the activation of search and competitive factors of educational motivation gives a highlevel educational result. The issues of optimizing feedback with students during a pandemic and remote learning are discussed in some publications $[10,11]$ and are aimed at finding the most effective models for developing the process of educational motivation and student support $[12,13]$. 
The authors S. Ozer, S.J. Schwartz pay great attention to the content side of student life, as an important stage of a successful start to future life and professional self-realization [14]. In their opinion, it is important to take into account not only professional competences, but also personal interests and motivation when developing curricula. Thus, rich social, leisure, and cultural practices play an important role in the development of personal interests, motivation to achieve personal and professional goals. They touch upon the issue of educational content management and transformation of educational programs [15].

The experience of successful application of the developed educational models for different age categories (from schoolchildren to people of retirement age) is shown in the article by G. Pennisi, F. Magrefi, N. Michelon, E. Sanyé-Mengual, G. Gianquinto [16]. Within the framework of social projects, such as the City Innovation Action "SALUS W SPACE", we see the involvement of people based on their interests in innovative activities that contribute to sustainable economic development and preservation of the ecology of urban areas. An important message for our study of leisure and socio-cultural practices of young people as a factor in the development of learning motivation is to attract people to positive practices based on their interests $[17,18,19,20]$.

\section{Conclusion}

Thus, the conducted empirical research shows fundamental differences in the models of social, leisure and cultural activity of students who successfully cope with the academic load and do not cope with it in full.

Students who successfully cope with the study load are characterized by:

- social ecosystem of a person, based mainly on virtual activities;

- educational motivation based on personal cognitive interest and supported by a healthy lifestyle.

For students who cannot cope with the studt load in full, it is typical:

- suppression of learning motivation by the intensity and variety of leisure practices;

- passive individual leisure practices in the virtual space with signs of narrowing of social communications.

Thus, to use the social, leisure, and cultural activity of students in order to increase educational motivation, it is necessary to control the construction of these practices.

\section{References}

1. L.I. Ermakova, D.N. Sukhovskaya, Lecture Notes in Networks and Systems 73, 647654 (2020)

2. M.C. Yang, J.S. Cheng, S.W. Yu, Social Behavior and Personality 40(2), 301-317 (2012)

3. V. Indrašiene, O. Merfeldaite, Pedagogika, 108, 104-110 (2012)

4. J.V. Kashina, I.V. Gluzman, N.A. Oparina, O.V. Ershova, S.Sh. Umerkaeva, International Journal of Criminology and Sociology 9, 2296-2302 (2020)

5. R. Shamionov, M. Grigoryeva, E.Grinina, A. Sozonnik, E3S Web of Conferences 210, 19019 (2020)

6. V. Kolyagina, K. Yadrov, S. Golubovich, A. Chebryakova, S. Mityanets, E3S Web of Conferences 210, 19027 (2020)

7. S. Rasciute, P. Downward, N. Simmons, Applied Economics, 52(31), 3379-3390 (2020) 
8. S. Park, J.H. Kim, Journal of Korean Academic Society of Nursing Education 26(4), 357-365 (2020)

9. O.V. Yureva, L.A. Burganova, O.Y. Kukushkina, G.P. Myagkov, D.V. Syradoev, Universal Journal of Educational Research 8(11 B), 5965-5971 (2020)

10. D. Pérez-Jorge, M.C. Rodríguez-Jiménez, E. Ariño-Mateo, F. Barragán-Medero, Sustainability (Switzerland) 12(20)-8631, 1-14 (2020)

11. R.L. Taylor, K. Knorr, M. Ogrodnik, P. Sinclair, International Journal for Academic Development 25(4), 350-362 (2020)

12. G. Glazkova, O. Mamonova, D. Gracheva, M. Pukhovskaya, Journal of Physical Education and Sport 20(5)-347, 2545-2553 (2020)

13. M. McLure, C. Sinkinson, Reference Services Review 48(3), 473-487 (2020)

14. S. Ozer, S.J. Schwartz, Nordic Psychology 72(3), 199-221 (2020)

15. J. Guerra, M. Ortiz-Rojas, M.A. Zúñiga-Prieto, T. De Laet, K. Verbert, British Journal of Educational Technology 51(4), 973-1001 (2020)

16. G. Pennisi, F. Magrefi, N. Michelon, E. Sanyé-Mengual, G. Gianquinto, Acta Horticulturae 1279, 45-51 (2020)

17. V.N. Goncharov, E.E. Nesmeyanov, O.U. Kolosova, V.V. Arutyunyan, V.A. Ivashova, Journal of Physics: Conference Series 1353(1) (2019)

18. V.A. Ivashova, G.V. Tokareva, E.G. Agalarova, Yu.B. Nadtochiy, I.V. Yushchenko, IOP Conference Series: Materials Science and Engineering 775(1) (2020)

19. I.S. Baklanov, O.A. Baklanova, A.M. Erokhin, N.N. Ponarina, G.A. Akopyan, Tarih Kültürve Sanat Araştırmaları 7(2) (2018)

20. O. Mukhoryanova, K. Hercegová, S. Kalyugina, O. Tretyakova, Terra Economicus, 16(4), 130-143 (2018) 